\title{
Circumventing traditional conditioning protocols in polymer membrane-based ion-selective electrodes
}

\author{
Michelle Rich, ${ }^{\dagger}$ Samantha T. Mensah, ${ }^{\dagger}$ Enrique Blanco-Martinez, ${ }^{\dagger}$ Percy, Calvo-Marzal, ${ }^{\dagger}$ Lukasz Mendecki, ${ }^{\ddagger}$ Ale- \\ ksandar Radu, ${ }^{\ddagger}$ and Karin Y. Chumbimuni-Torres ${ }^{*}{ }^{\dagger}$ \\ ${ }^{\dagger}$ Department of Chemistry, P.O. Box 2500o, University of Central Florida, Orlando, Florida 32816-2366, United \\ States \\ ${ }^{\ddagger}$ Lennard-Jones Laboratories, Birchall Centre, Keele University, Keele, Staffordshire $\mathrm{ST}_{5}{ }_{5} \mathrm{BG}$, United Kingdom
}

ABSTRACT: Preparation of ISEs often requires long and complicated conditioning protocols limiting their application as tools for in field measurements. Herein, we eliminated the need for conditioning by loading the membrane cocktail with primary ion solution. This protocol significantly shortens the preparation time of ISEs yielding functional electrodes with submicromolar detection limits.

The scientific research in ion-selective electrodes (ISEs) has gained momentum within the last years due to improvements in the limits of detection and selectivity, becoming now applicable for trace-level measurements by understanding transmembrane ion fluxes. ${ }^{1}$ The response of ISEs can be described by the phase boundary potential, $\mathrm{E}_{\mathrm{PB}}$, according the following equation:

$E_{P B}=E^{0}+\frac{R T}{z_{I} F} \ln \frac{a_{I(a q)}}{a_{I(o r g)}}$

Here $\mathrm{a}_{\mathrm{I}(\mathrm{aq})}$ and $\mathrm{a}_{\mathrm{I} \text { (org) }}$ are the activities of primary ion (I) of charge $\mathrm{z}$ in aqueous and organic phases respectively, while $E^{o}, R, T$, and $F$ are the standard potential, gas constant, temperature and Faraday constant, respectively. When $\mathrm{a}_{\mathrm{I} \text { (org) }}$ is kept constant, the equation 1 reduces to the well-known Nernst equation:

$E_{P B}=E^{0}+\frac{R T}{z_{I} F} \ln a_{I(a q)}$

In order to render an ion-selective membrane functional, the ionophore and lipophilic ionic sites are required. One of the major roles of ionophore is to make relatively strong complexes with the primary ion, thereby establishing their constant activity in the membrane. ${ }^{2}$ For more details see Equations SI-SI5 in the supporting information. The role of the lipophilic ionic sites is to provide ion-exchange properties. For cation selective membrane, this process could be described by the following equilibrium:

$$
a_{I(a q)}^{Z I+}+n L_{\text {org }}+M_{\text {org }}^{+} R_{\text {org }}^{-} \rightarrow\left[I L_{n}\right]_{\text {org }}^{z I+}+M_{a q}^{+}+R_{\text {org }}^{-}
$$

where $\mathrm{L}$ is a ligand (ionophore) that forms ion-ionophore complex with ion I of stoichiometry n. $M_{o r g}^{+} R_{\text {org }}^{-}$is a lipophilic ion exchanger composed of lipophilic anion $\mathrm{R}^{-}$and its counterion $\mathrm{M}^{+}$. Partitioning of I from aqueous sample into the membrane results in its exchange with $\mathrm{M}^{+}$. Anion $R_{\text {org }}^{-}$remains in the membrane thereby rendering the membrane permselective while preserving the charge balance. ${ }^{3}$ In a typical experimental protocol for the preparation of ion-selective membranes the ion-exchange process is obtained by conditioning (soaking) the membrane in an aqueous solution containing the ion I (traditional protocol). ${ }^{4}$

Significant effort in ISEs field has been spent on researching ways to miniaturize ${ }^{5-9}$ and optimize/simplify the preparation of ISEs. ${ }^{10-12}$ Reducing or eliminating the need for the conditioning step prior to the use of the electrodes is an important step for devising a simple, practical protocol for ISEs applications. ${ }^{12}$ This would enable nontrained personnel to use ISEs quickly and reliably. In this work we propose a simple alteration of the sensor's conditioning protocol. Instead of placing the ISEs in a solution of primary ions I, solution is added directly into the membrane cocktail prior to its casting. The concentration of that solution is calculated to allow for stoichiometric exchange of I and M. Consequently, ions I are present in the membrane facilitating the formation of ion-ionophore complex according to the following equilibrium:

$I_{\text {org }}^{Z I+}+n L_{\text {org }}+R_{\text {org }}^{-} \rightarrow\left[I L_{n}\right]_{\text {org }}^{Z I+}+R_{\text {org }}^{-}$ 
Therefore, upon casting, the membrane is already preloaded with complexed ions I in the form of the ionionophore complex $\left[I L_{n}\right]_{\text {org }}^{z I+}$. Satisfaction of stoichiometry implies that the concentration of the complex in the membrane is constant thus fulfilling the requirements for application of Equation 2. The well-formed Nernstian responses are therefore expected for these nonconditioned ISEs.

\section{EXPERIMENTAL}

\section{Reagents}

4-tert-Butylcalix[4]arene-tetraacetic acid tetraethyl ester (sodium ionophore $\mathrm{X}$ ), o-xylylenebis $(N, N$ diisobutyldithiocarbama-te) (copper(II) ionophore I), potassium tetrakis [3,5 bis(trifluorome-thyl) phenyl]borate (KTFPB), sodium tetrakis[3,5 bis(trifluoro-methyl) phenyl]borate (NaTFPB), tridodecylmethylammonium nitrate (TDMANO ${ }_{3}$ ), bis(2-ethylhexyl) sebacate (DOS), high molecular weight poly(vinyl) chloride (PVC), and tetrahydrofuran (THF), all of Selectophore grade, were purchased from Sigma-Aldrich. [9]Mercuracarborand-3 ( $\left.\mathrm{MC}_{3}\right)$ was synthesized in house as described previously. ${ }^{14}$ The salts $\mathrm{AgPF}_{6}, \mathrm{AgNO}_{3}, \mathrm{NaNO}_{3}, \mathrm{NaI}$, and $\mathrm{KCl}$ were also obtained from Sigma-Aldrich. All aqueous solutions were prepared in ultra-pure water obtained with Purelab Ultra water purification system (resistance $18 \mathrm{M} \Omega \mathrm{cm}$ ).

\section{Membranes}

The $\mathrm{Na}^{+}$-selective membrane contained $10.0 \mathrm{mmol} \mathrm{kg}{ }^{-1}$ of sodium ionophore $X$ and $5.0 \mathrm{mmol} \mathrm{kg}{ }^{-1}$ of NaTFPB. The $\mathrm{Ag}^{+}$-selective membrane contained $10.0 \mathrm{mmol} \mathrm{kg}{ }^{-1}$ of copper (II) ionophore I and $5.0 \mathrm{mmol} \mathrm{kg}^{-1}$ of NaTFPB. ${ }^{15}$ The IISEs contained $1.0 \mathrm{mmol} \mathrm{kg}^{-1}$ of $\mathrm{MC}_{3}$ and $0.75 \mathrm{mmol} \mathrm{kg}$ of $\mathrm{TDMANO}_{3}$. Ion-selective membranes were prepared by dissolving the above-mentioned components together with PVC (33.3 wt \%) and DOS (66.6 wt \%) in $2 \mathrm{~mL}$ THF and the resulting cocktail was vortexed for $30 \mathrm{~min}$.

To avoid conditioning steps, $25 \mu \mathrm{L}$ of o.1 $\mathrm{M} \mathrm{AgNO}_{3}$ solution was added to the $\mathrm{Ag}^{+}$-selective membrane and $1.8 \mu \mathrm{L}$ of o.1 M NaI solution was added to the I--selective membrane before vortexing. No additional solution was added for the $\mathrm{Na}^{+}$-selective membrane. Control membranes were also prepared: For $\mathrm{Ag}^{+}$-selective ISEs, no $\mathrm{AgNO}_{3}$ solution was added, for $\mathrm{I}^{-}$-selective control membranes, no $\mathrm{NaI}$ solution was added. For $\mathrm{Na}^{+}$-selective electrodes, KTFPB was used as ion-exchanger instead of NaTFPB. The resulting membrane cocktail was cast into a glass ring ( 26 $\mathrm{mm}$ inner diameter) secured to a glass plate, and the solvent was allowed to evaporate overnight. This resulted in a membrane film with a thickness of approximately $200 \pm$ $10 \mu \mathrm{m}$ (obtained using caliper).

\section{Electrodes}

The ISEs were prepared as follows: Firstly, a $3.2 \mathrm{~mm}$ diameter disk was cut from the parent membrane film and adhered to the end of a PVC tube $(2 \mathrm{~cm}$ length, $1.6 \mathrm{~mm}$ i.d.) using THF. The other end of the tube was fixed to a 1 $\mathrm{mL}$ pipette tip that held the inner filling solution. Inner filling solutions for the $\mathrm{Na}^{+}$-ISE, $\mathrm{Ag}^{+}$-ISE, and $\mathrm{I}^{-}$-ISE were $1.0 \times 10^{-3} \mathrm{M} \mathrm{NaNO}_{3}$, $1.0 \times 10^{-3} \mathrm{M} \mathrm{AgNO}_{3}$ and $1.0 \times 10^{-3} \mathrm{M} \mathrm{NaI}$, respectively. A diaphragm separated the internal filling solutions from the reference half-cell $(\mathrm{Ag} / \mathrm{AgCl}$ in $0.1 \mathrm{M}$ $\mathrm{KCl})$.

\section{EMF measurements}

Potential measurements of the non-conditioned ISEs began immediately after adding the inner filling solution to the electrode. Measurements were carried out in $100 \mathrm{~mL}$ polypropylene beakers. A high-input impedance $\left(10^{15} \Omega\right)$ EMF-16 multichannel data acquisition system (Precision Electrochemistry EMF Interface, Lawson Laboratories) was used to monitor the potentials, at room temperature $\left(22{ }^{\circ} \mathrm{C}\right)$ and under constant stirring. A double junction $\mathrm{Ag} / \mathrm{AgCl} / 3 \mathrm{M} \mathrm{KCl} / \mathrm{M}$ LiOAc (Metrohm AG) was used as the reference electrode. All EMF values were corrected for liquid-junction potentials according to the Henderson equation, and activity coefficients were calculated by the Debye-Hückel approximation.

\section{Selectivity measurements}

ISEs for selectivity measurements were prepared according to the protocol described in 'Membranes and Electrodes' with some modifications. For $\mathrm{Na}^{+}$-ISEs, lipophilic ion exchanger - KTFPB was used instead of NaTFPB. $\mathrm{Ag}^{+}$ cocktail solution was loaded with $5 \mathrm{mmol} \mathrm{kg} \mathrm{kg}^{-1}$ of $\mathrm{NaNO}_{3}$ while $5 \mathrm{mmol} \mathrm{kg}^{-1}$ of $\mathrm{KNO}_{3}$ were added into $\mathrm{I}^{-}$membrane solution. Inner filling solutions for the $\mathrm{Na}^{+}-$ISE, $\mathrm{Ag}^{+}$-ISE, and I-ISE were $1.0 \times 10^{-3} \mathrm{M} \mathrm{KNO}_{3}$, $1.0 \times 10^{-3} \mathrm{M} \mathrm{NaNO}_{3}$ and $1.0 \times 10^{-3} \mathrm{M} \mathrm{KNO}_{3}$, respectively. Responses towards all ions were recorded according to separate solution method as described by Bakker. ${ }^{16}$

\section{RESULTS AND DISCUSSION}

\section{Response characteristics}

The establishment of the ion-ionophore complex equilibrium is key to create the potential gradient at the interface of the electrode while maintaining constant activity of analyte ions inside the membrane. ${ }^{17}$ By understanding, the ion flux at the membrane/sample interface, it enables the ion-selective membrane composition to be optimized while avoiding long conditioning steps. The equilibrium between complexed and free ionophore in the membrane could be obtained during the preparation of the membrane by adding the ion of interest directly to the membrane cocktail at stoichiometrically optimized amount. In the preparation step, consideration should be given to the lipophilicity of the counterion of the loading solution (see the Supporting Information Figure S1 and accompanying discussion).

Thus, Figure 1A shows the calibration curve of the nonconditioned $\mathrm{Na}^{+}$-ISE that contains NaTFPB as the ionexchanger. This calibration curve displays a Nernstian 
slope of $57.05 \pm 2.03 \mathrm{mV}$ decade $^{-1}$ and a submicromolar limit of detection of $3.24 \times 10^{-7} \pm 0.02 \mathrm{M}$, showing a similar performance as the conditioned $\mathrm{Na}^{+}$-ISEs previously reported using a similar membrane composition. ${ }^{18}$ Conversely, the calibration curve of the non-conditioned $\mathrm{Na}^{+}-$ ISE control membranes containing KTFPB instead of NaTFPB as the ion-exchanger (Figure $1 B$ ) demonstrated a super-Nernstian behavior upon initial exposure to sodium ions. This is caused by a flux of sodium ions from the sample solution into the bulk of ion-selective membrane as previously reported in the literature.
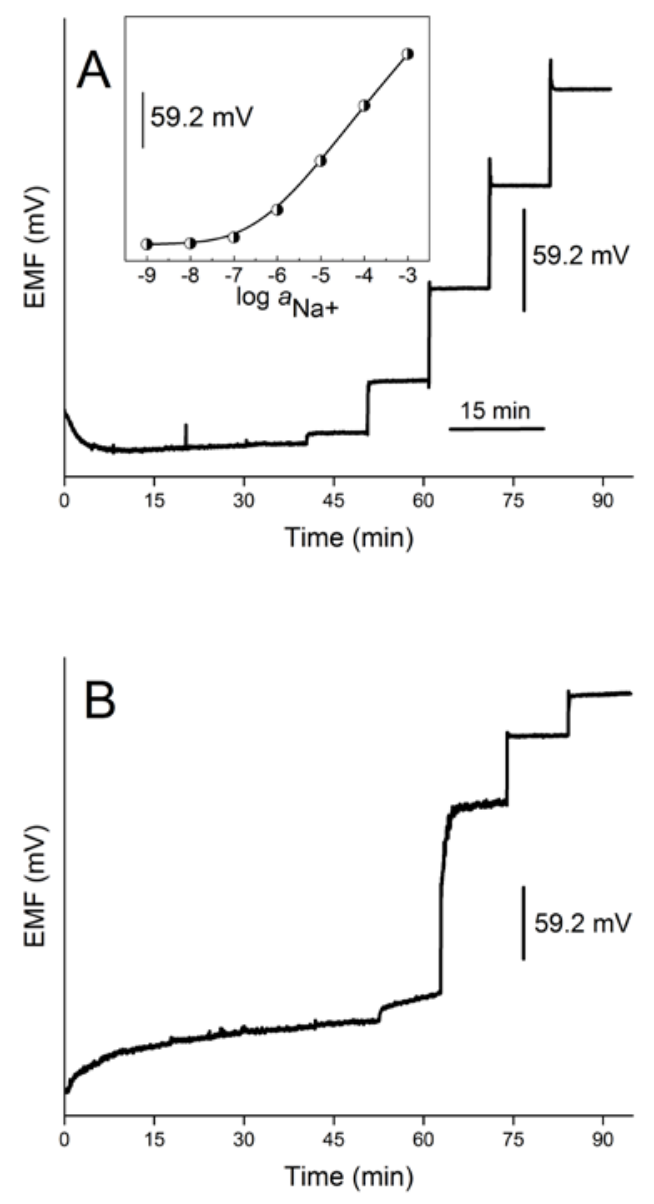

Figure 1. Trace lines for the non-conditioned $\mathrm{Na}^{+}$-ISE containing A) NaTFPB and B) KTFPB as the ion-exchanger. Inset in Figure $1 \mathrm{~A}$ displays the respective calibration curve. All other components of the membranes in A and B are the same.

Similarly, the calibration curve (Figure $2 \mathrm{~A}$ ) of the nonconditioned $\mathrm{Ag}^{+}$-ISE with preloaded $\mathrm{AgNO}_{3}$ solution also displays a Nernstian slope of $58.05 \pm 0.77 \mathrm{mV}$ decade $^{-1}$ and a limit of detection of $2.69 \times 10^{-7} \pm 0.03 \mathrm{M}$, that are similar to the traditional conditioned $\mathrm{Ag}^{+}$-ISE as reported in the literature, but with higher limit of detection. ${ }^{19}$ The small discrepancy in the observed and reported detection limits could be caused by the trans-membrane ion flux from the inner filling solution in the direction of the sample. ${ }^{20}$ This could disturb the local equilibrium at the sam- ple/membrane interface consequently worsening the detection limit of ISEs.

On the other hand, a super-Nernstian response was observed (Figure $2 \mathrm{~B}$ ) for the non-conditioned $\mathrm{Ag}^{+}$-ISE in which no $\mathrm{AgNO}_{3}$ solution was added to the cocktail solution (control membrane). Similarly to the $\mathrm{Na}^{+}$-ISE the super-Nernstian response was also observed due to the initial exposure of ISEs to the primary ions (silver ions). In addition, control membranes were subsequently conditioned for 2, 4, 6, 8, 10, 12 and $24 \mathrm{~h}$ in $1.0 \times 10^{-3} \mathrm{M}$ of $\mathrm{AgNO}_{3}$ solution and a minimum of $12 \mathrm{~h}$ was required to obtain ISEs with Nernstian response slopes (data not shown). Moreover, traditionally prepared $\mathrm{Ag}^{+}$-ISEs exhibited similar response characteristics (lower detection limits and Nernstian behavior, Figure S2) to those conditioned according to the proposed methodology. This demonstrates the practicality of adding the solution of primary ions into the membrane cocktail to further reduce the preparation time of ISEs.
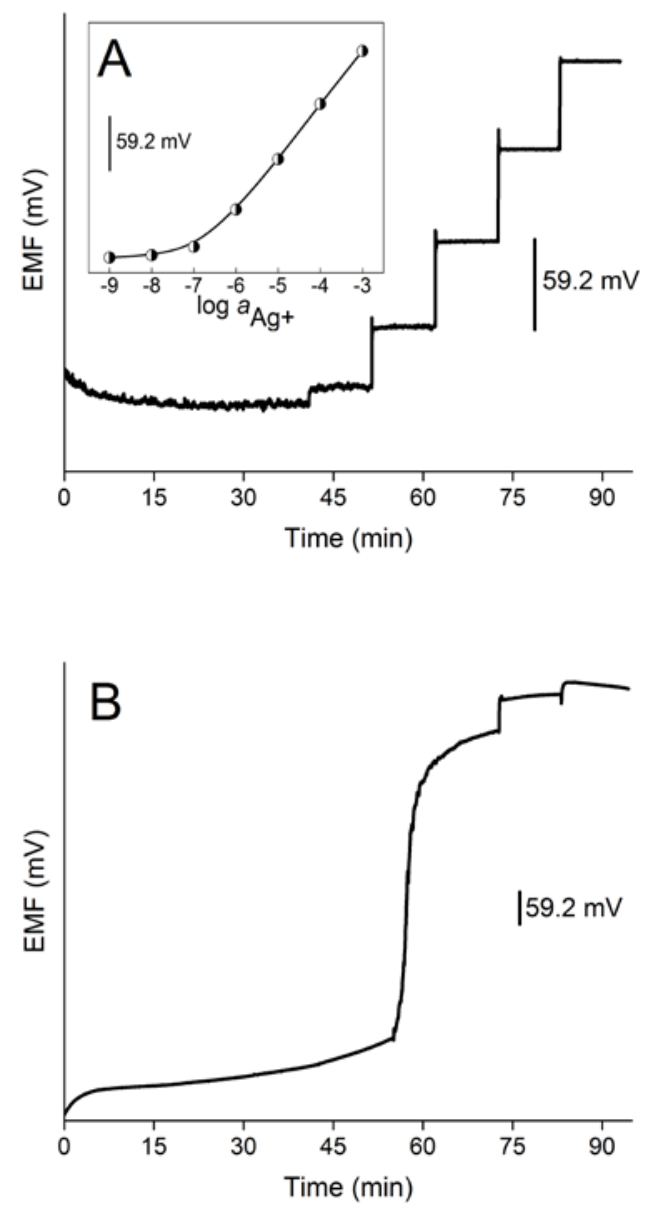

Figure 2. Trace lines for the non-conditioned $\mathrm{Ag}^{+}$-ISEs containing A) $\mathrm{AgNO}_{3}$ solution and $\mathrm{B}$ ) without $\mathrm{AgNO}_{3}$ solution in 
the membrane. Inset in $2 \mathrm{~A}$ displays the respective calibration curve. All other components of the membranes in A and B are the same.

The Nernstian behavior of the non-conditioned cationselective system that was doped with the primary ion during the membrane preparation for sodium and silver ions were also tested for an anion-selective system. As described in the experimental part the I-ISEs were prepared with and without $\mathrm{NaI}$ in the membrane composition. As shown in Figure $3 \mathrm{~A}$, the calibration curve of the nonconditioned $\mathrm{I}^{-}$-ISEs, where $\mathrm{NaI}$ solution was added into the cocktail, presents a Nernstian slope of $57.59 \pm 2.56 \mathrm{mV}$ decade $^{-1}$ and a limit of detection of $8.51 \times 10^{-8} \pm 0.07 \mathrm{M}$. This is in good agreement with the traditional conditioned I--ISEs based on the same ionophore as reported in the literature, but the observed detection limit was higher by one order of magnitude. ${ }^{21}$ The non-optimal behavior of MC-3 based ISEs at the lower detection end could be caused by the strong interference from the hydroxide ions. ${ }^{22}$ Similar as in cation system, when a solution of the analyte was not added into the cocktail solution (blank membranes for iodide) a super-Nernstian response was observed (Figure 3B).

The non-conditioned ISEs were also characterized in terms of selectivity using an unbiased method. Therefore, each electrode was conditioned in a solution of less discriminated interfering ion prior to the performed measurements. ${ }^{16}$ Table 1 shows the selectivity values obtained for $\mathrm{Na}^{+}-\mathrm{ISE}, \mathrm{Ag}^{+}$-ISE and I--ISE.

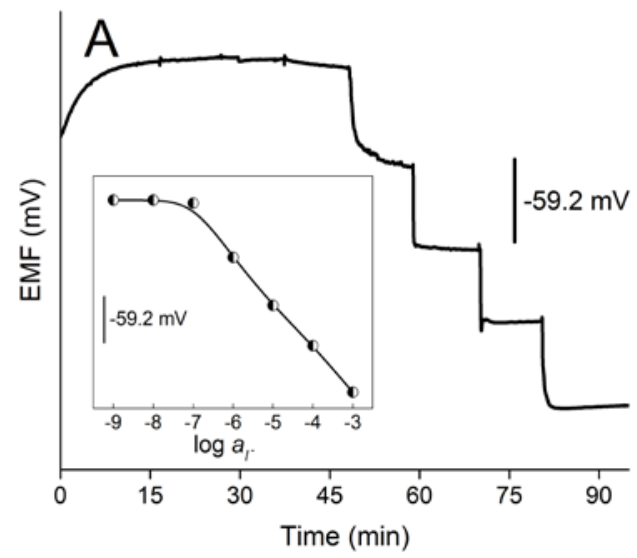

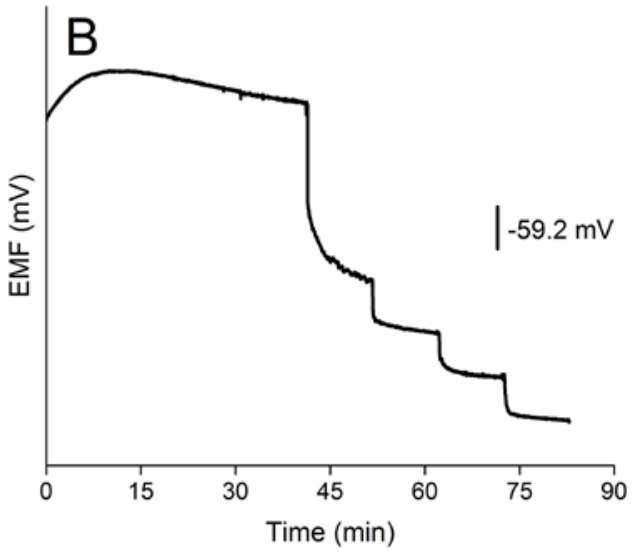

Figure 3. Figure 3. Trace lines for the non-conditioned I-ISEs containing A) NaI solution and B) and without NaI solution in the membrane. Inset in $3 \mathrm{~A}$ displays the respective calibration curve. All other components of the membranes in A and $\mathrm{B}$ are the same.

Table 1. Unbiased selectivity coefficients obtained for the $\mathrm{Na}^{+}$-ISEs (slope: $50.23 \pm 0.09 \mathrm{mV}$ decade ${ }^{-1}$ ), $\mathrm{Ag}^{+}$ISEs (slope: $57.32 \pm 3.27 \mathrm{mV}$ decade $^{-1}$ ) and $I^{-}$-ISEs (slope: - $56.33 \pm 0.17 \mathrm{mV}$ decade $^{-1}$ ) with corresponding slope values for interfering ions.

\begin{tabular}{|c|c|c|}
\hline Ion $J^{Z+}$ & $K_{N a, J}^{p o t}$ & Slope (mV decade ${ }^{-1}$ ) \\
\hline $\mathrm{K}^{+}$ & $-1.1 \pm 0.1$ & $56.35 \pm 0.13$ \\
\hline $\mathrm{H}^{+}$ & $-4.5 \pm 0.3$ & $51.61 \pm 1.80$ \\
\hline $\mathrm{Li}^{+}$ & $-5.2 \pm 0.3$ & $53.03 \pm 1.39$ \\
\hline Ion $J^{Z+}$ & $K_{A g, J}^{p o t}$ & Slope (mV decade $\left.{ }^{-1}\right)$ \\
\hline $\mathrm{Na}^{+}$ & $-6.9 \pm 1.2$ & $53.11 \pm 1.15$ \\
\hline $\mathrm{K}^{+}$ & $-6.4 \pm 0.9$ & $54 \cdot 51 \pm 0.68$ \\
\hline $\mathrm{H}^{+}$ & $-7.6 \pm 0.5$ & $50.58 \pm 3.23$ \\
\hline $\mathrm{Cu}^{+}$ & $-8.7 \pm 0.6$ & $59.91 \pm 0.61$ \\
\hline Ion $J^{Z+}$ & $K_{I, J}^{p o t}$ & Slope $\left(\mathrm{mV}\right.$ decade $\left.{ }^{-1}\right)$ \\
\hline $\mathrm{Br}^{-}$ & $-1.3 \pm 0.0$ & $-64.71 \pm 2.92$ \\
\hline $\mathrm{Cl}^{-}$ & $-1.3 \pm 0.0$ & $-64.65 \pm 2.71$ \\
\hline $\mathrm{NO}_{3}^{-}$ & $-2.1 \pm 0.0$ & $-55.93 \pm 4.00$ \\
\hline
\end{tabular}

\section{CONCLUSIONS}


In this work, new methodology for the preparation of ISEs with reduced equilibration time is proposed. This was achieved by adding a small aliquot of primary ions into the cocktail solution giving rise to ISEs with submicromolar detection limits. This facilitates the use of ISEs in the field for non-trained personnel. Further characterization has to be carried out to fully understand the properties on the sensor prepared according to the proposed modified protocol.

\section{ASSOCIATED CONTENT}

\section{Supporting Information}

Further experimental details. This material is available free of charge via the Internet at http://pubs.acs.org."

\section{AUTHOR INFORMATION}

\section{Corresponding Author}

* Karin.ChumbimuniTorres@ucf.edu;

\section{Present Addresses}

${ }^{\dagger}$ Department of Chemistry, P.O. Box 2500o, University of Central Florida, Orlando, Florida 32816-2366.

\section{Author Contributions}

All The manuscript was written through contributions of all authors. All authors have given approval to the final version of the manuscript.

\section{Notes}

The authors declare no competing financial interests.

\section{ACKNOWLEDGMENT}

The authors thank to the Office of Research and Commercialization, College of Science and the Department of Chemistry at University of Central Florida, Royal Society (RG120118), and Marie Curie IRSES Grant (IBS Network; R6810 B475) for financial support.

\section{REFERENCES}

(1) Ngeontae, W.; Xu, Y.; Xu, C.; Aeungmaitrepirom, W.; Tuntulani, T.; Pretsch, E.; Bakker, E. Anal. Chem. 2007, 79 (22), 8705-8711.

(2) Duncan, D. M.; Cockayne, J. S. Sens. Actuators B Chem. 2001, 73 (2-3), 228-235.

(3) Woźnica, E.; Mieczkowski, J.; Michalska, A. The Analyst 2011, 136 (22), 4787.

(4) Lazo Fraga, A. R.; Calvo Quintana, J.; Destri, G.; Giamblanco, N.; Toro, R. G.; Punzo, F. J. Solid State Electrochem. 2012, 16 (3), 901-909.

(5) Anastasova-Ivanova, S.; Mattinen, U.; Radu, A.; Bobacka, J.; Lewenstam, A.; Migdalski, J.; Danielewski, M.; Diamond, D. Sens. Actuators B Chem. 2010, 146 (1), 199-205.

(6) Goldberg, H. D.; Brown, R. B.; Liu, D. P.; Meyerhoff, M. E. Sens. Actuators B Chem. 1994, 21 (3), 171-183.

(7) Gyurcsanyi, R. Talanta 2004, 63 (1), 89-99.

(8) Hart, J. P.; Crew, A.; Crouch, E.; Honeychurch, K. C.; Pemberton, R. M. Anal. Lett. 2004, 37 (5), 789-830.

(9) Renedo, O. D.; Alonso-Lomillo, M. A.; Martínez, M. J. A. Talanta 2007, 73 (2), 202-219.

(10) Bakker, E.; Bhakthavatsalam, V.; Gemene, K. L. Talanta 2008, 75 (3), 629-635.
(11) Bhakthavatsalam, V.; Shvarev, A.; Bakker, E. The Analyst 2006, 131 (8), 895-900.

(12) Radu, A.; Anastasova, S.; Fay, C.; Diamond, D.; Bobacka, J.; Lewenstam, A. IEEE, 2010; pp 1487-1490.

(13) Eriksen, R. S.; Mackey, D. J.; Alexander, P.; De Marco, R.; Wang, X. D. J. Environ. Monit. JEM 1999, 1 (5), 483-487.

(14) Zinn, A. A.; Zheng, Z.; Knobler, C. B.; Hawthorne, M. F. J. Am. Chem. Soc. 1996, 118 (1), 70-74.

(15) Szigeti, Z.; Malon, A.; Vigassy, T.; Csokai, V.; Grün, A.; Wygladacz, K.; Ye, N.; Xu, C.; Chebny, V. J.; Bitter, I.; Rathore, R.; Bakker, E.; Pretsch, E. Anal. Chim. Acta 20o6, 572 (1), 1-10.

(16) Bakker, E. Anal. Chem. 1997, 69 (6), 1061-1069.

(17) Mathison, S.; Bakker, E. Anal. Chem. 1998, 70 (2), 303-309.

(18) Kimura, K.; Yoshinaga, M.; Funaki, K.; Shibutani, Y.; Yakabe, K.; Shono, T.; Kasai, M.; Mizufune, H.; Tanaka, M. Anal. Sci. 1996, 12 (1), 67-70.

(19) Chumbimuni-Torres, K. Y.; Rubinova, N.; Radu, A.; Kubota, L. T.; Bakker, E. Anal. Chem. 2006, 78 (4), 1318-1322.

(20) Ceresa, A.; Radu, A.; Peper, S.; Bakker, E.; Pretsch, E. Anal. Chem. 2002, 74 (16), 4027-4036.

(21) Malon, A.; Radu, A.; Qin, W.; Qin, Y.; Ceresa, A.; MajZurawska, M.; Bakker, E.; Pretsch, E. Anal. Chem. 20o3, 75 (15), 3865-3871.

(22) Radu, A.; Bakker, E. Chem. Anal. 2005, 50 (1), 71-83. 
